\title{
IMAGE
}

\section{Insights Image for "Repetitive noxious stimuli during early development affect acute and long-term mechanical sensitivity in rats"}

\author{
Nynke J. van den Hoogen (iD ${ }^{1,2}$, J. Patijn ${ }^{1}$, D. Tibboel ${ }^{3}$ and E. A. Joosten ${ }^{1,2}$ \\ Pediatric Research (2020) 87:178; https://doi.org/10.1038/s41390-019-0575-5
}

Anatomy of the adult pain pathway. Primary afferent fibers transmit nociceptive information to the spinal cord dorsal horn. Here, the nociceptive signal is conveyed to projection neurons, transmitting the information to supraspinal areas. Signals arriving in the somatosensory cortex code for intensity and location of pain. Signals arriving in brainstem areas such as the periaquaductal grey (PAG) and rostroventral medulla (RVM) ensure a feedback system, modulating the spinal pain network by descending inhibition. The numbers indicate in which areas development is affected by (repetitive) neonatal pain. (1) Afferent fiber sprouting is increased, allowing more pain signal to enter the spinal cord. (2) Within the dorsal horn, several developmental processes are affected, leading to a more excitable environment. This leads to increased pain transmission. (3) Descending modulation is affected, leading to an altered feedback response after re-injury.

\section{REFERENCE}

van den Hoogen, N. J., Patijn, J., Tibboel, D. \& Joosten, E. A. Repetitive noxious stimuli during early development affect acute and long-term mechanical sensitivity in rats. Pediatr Res. (2019). https://doi.org/10.1038/s41390-019-0420-x [Epub ahead of print].

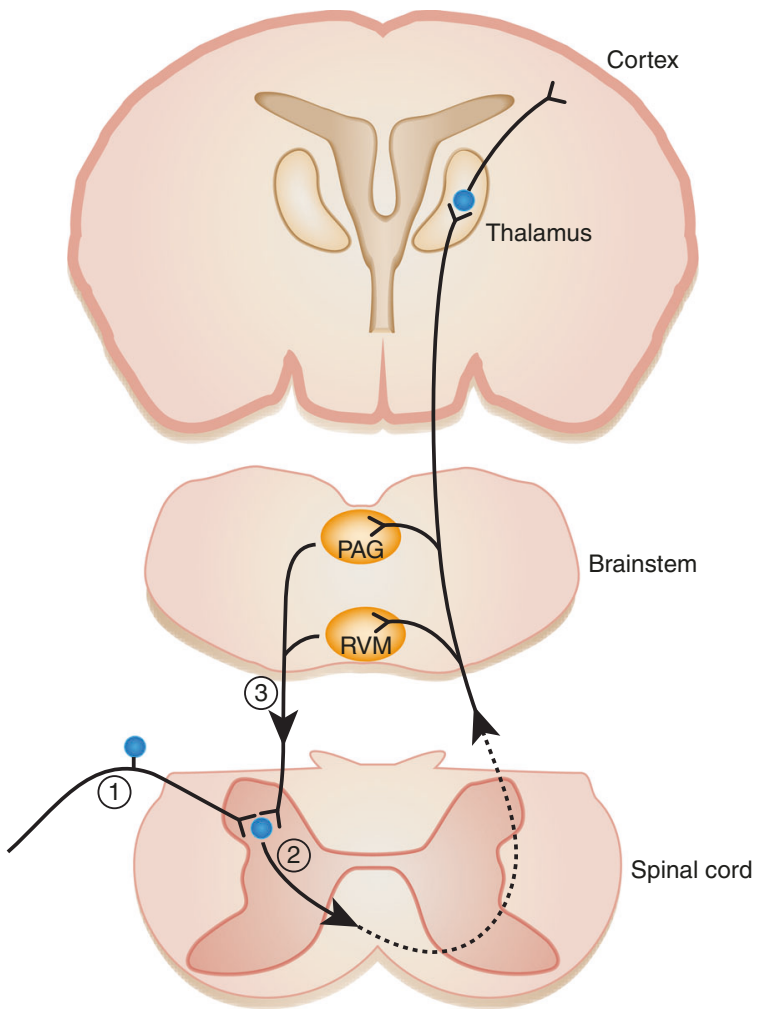

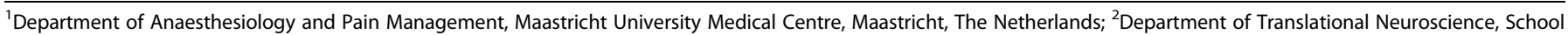

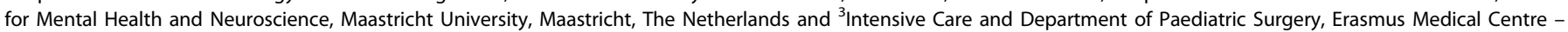
Sophia Children's Hospital, Rotterdam, The Netherlands

Correspondence: Nynke J. van den Hoogen (nynkevdhoogen@gmail.com)

Received: 30 August 2019 Accepted: 30 August 2019

Published online: 14 September 2019 